Supplement of

\title{
3D Radiative Heating of Tropical Upper Tropospheric Cloud Systems derived from Synergistic A-Train Observations and Machine 5 Learning
}

Claudia J. Stubenrauch ${ }^{1}$, Giacomo Caria ${ }^{1}$, Sofia E. Protopapadaki ${ }^{2}$, Friederike Hemmer ${ }^{1}$

${ }^{1}$ Laboratoire de Météorologie Dynamique / Institut Pierre-Simon Laplace, (LMD/IPSL), Sorbonne Université, Ecole Polytechnique, CNRS, Paris, France

$10{ }^{2}$ COOPETIC, Paris, France

Correspondence to: Claudia J. Stubenrauch (stubenrauch@ Imd.polytechnique.fr) 

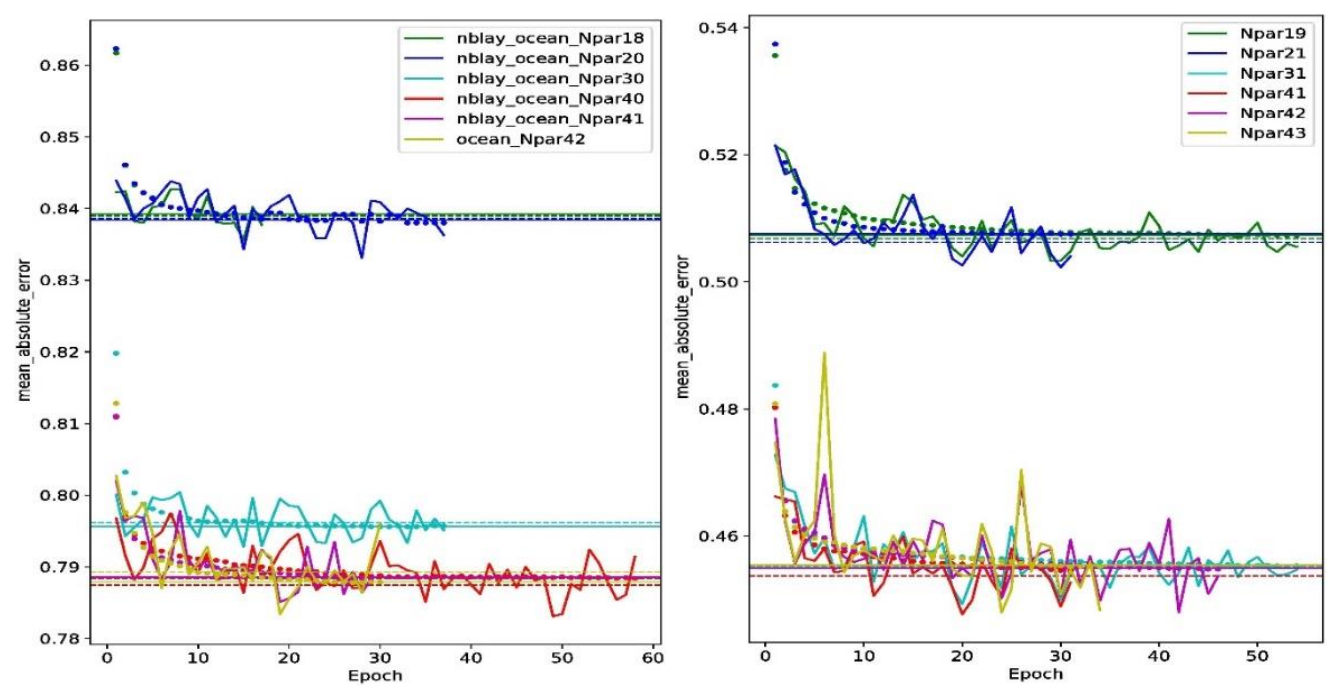

15 Figure S1: Sensitivity results concerning surface, atmospheric and cloud input parameters for the prediction of LW (left) and SW (right) radiative heating rates of clouds: Mean absolute error (in K/day) of training (dots) and validation (lines) for the experiments 1-6 for LW and 2 ï 6 for SW, using the parameters listed in Table 1.


Figure S2: Sensitivity results concerning surface, atmospheric and cloud input parameters for the prediction of LW (left) and SW (right) radiative heating rates of clear sky scenes as determined by CIRS: Mean absolute error (in K/day) of training (dots) and validation (lines) for the parameters listed in Table 1. 

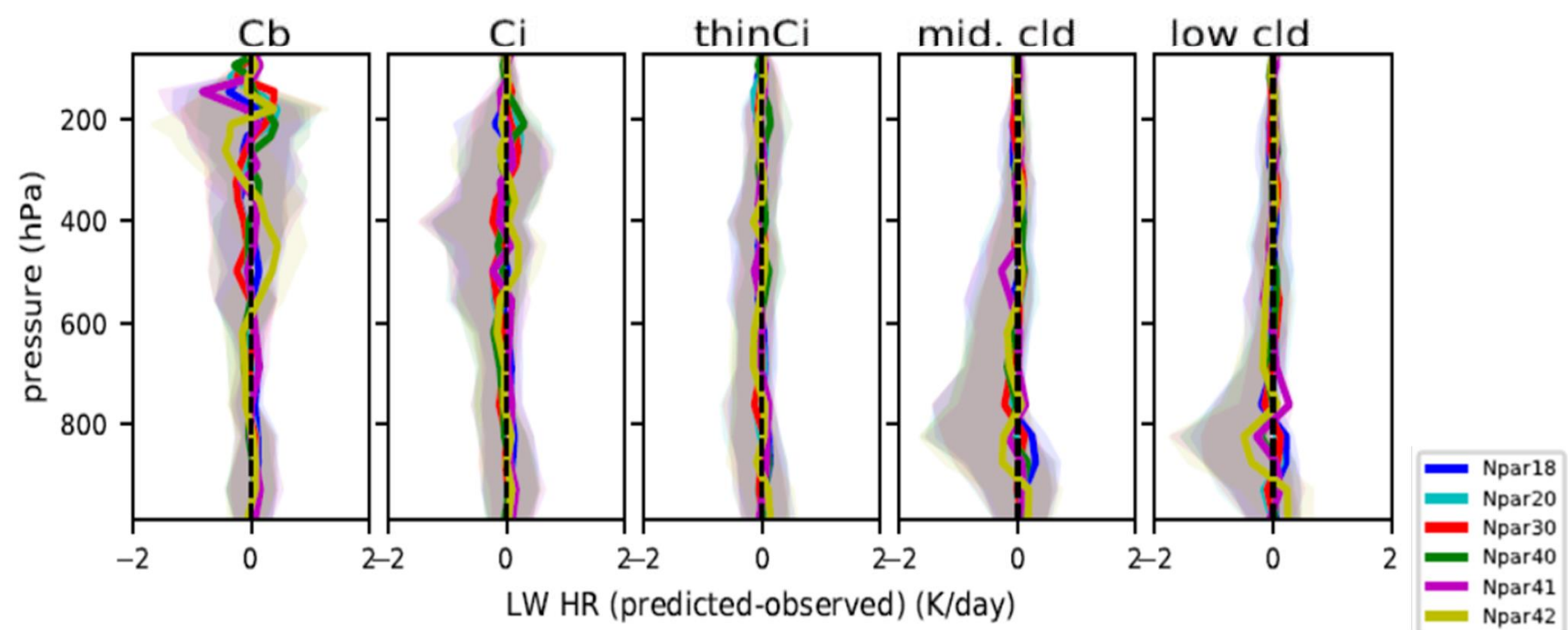

25

LW HR (predicted-observed) (K/day)
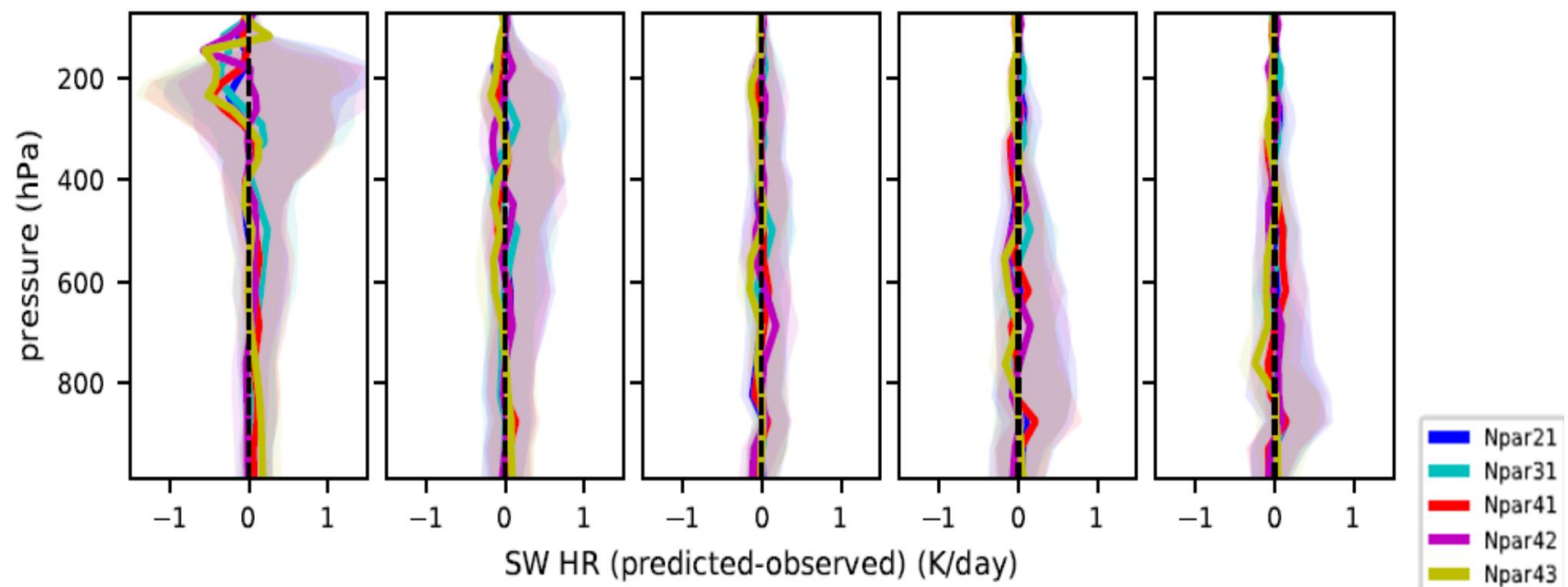

Figure S3: Sensitivity results concerning surface, atmospheric and cloud input parameters for the prediction of cloud LW radiative heating rates (above) and SW radiative heating rates (below): difference between predicted and observed vertical profiles of the validation dataset, separately for $\mathrm{Cb}$, Cirrus, thin Cirrus, mid- and low-level clouds, as identified by AIRS-CIRS, over tropical ocean. 30\% and 70\% quantiles of the distributions are also shown. Compared are results of the experiments 1-6 (above) and 2-6 (below), using the input parameters listed in Table 1. 

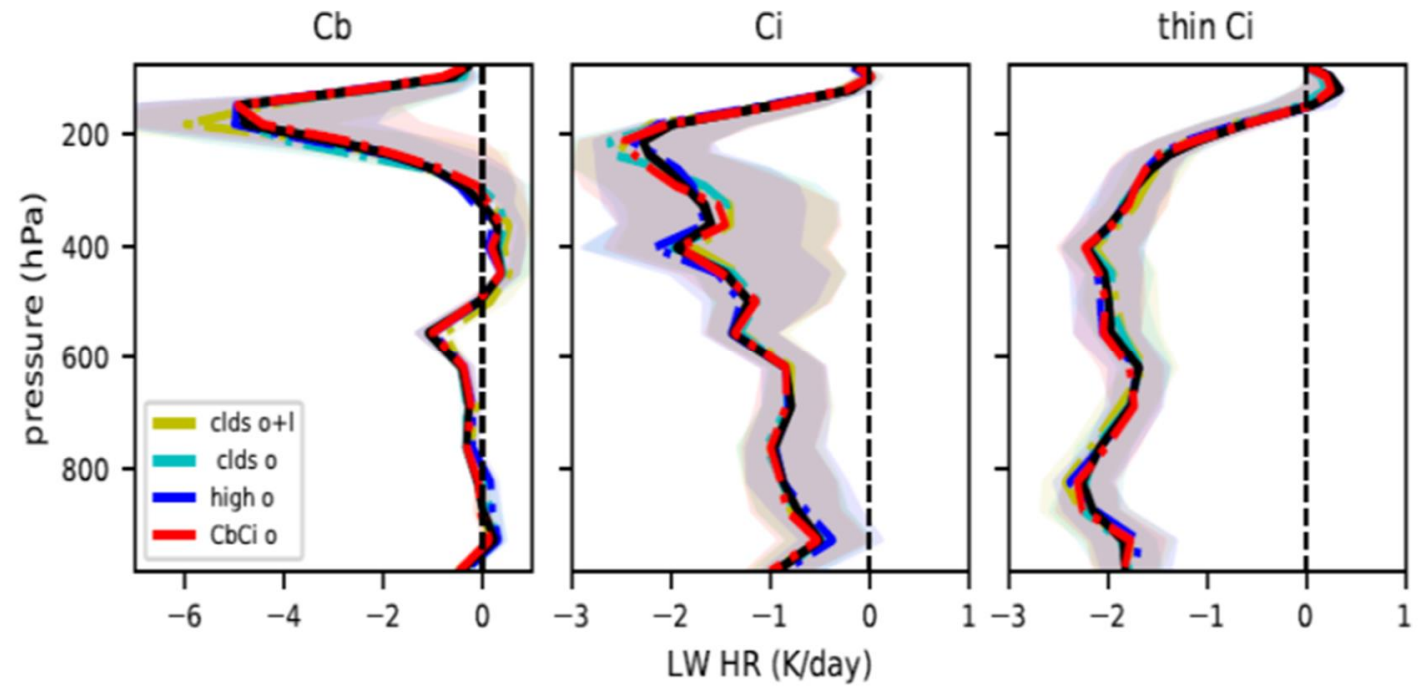

35
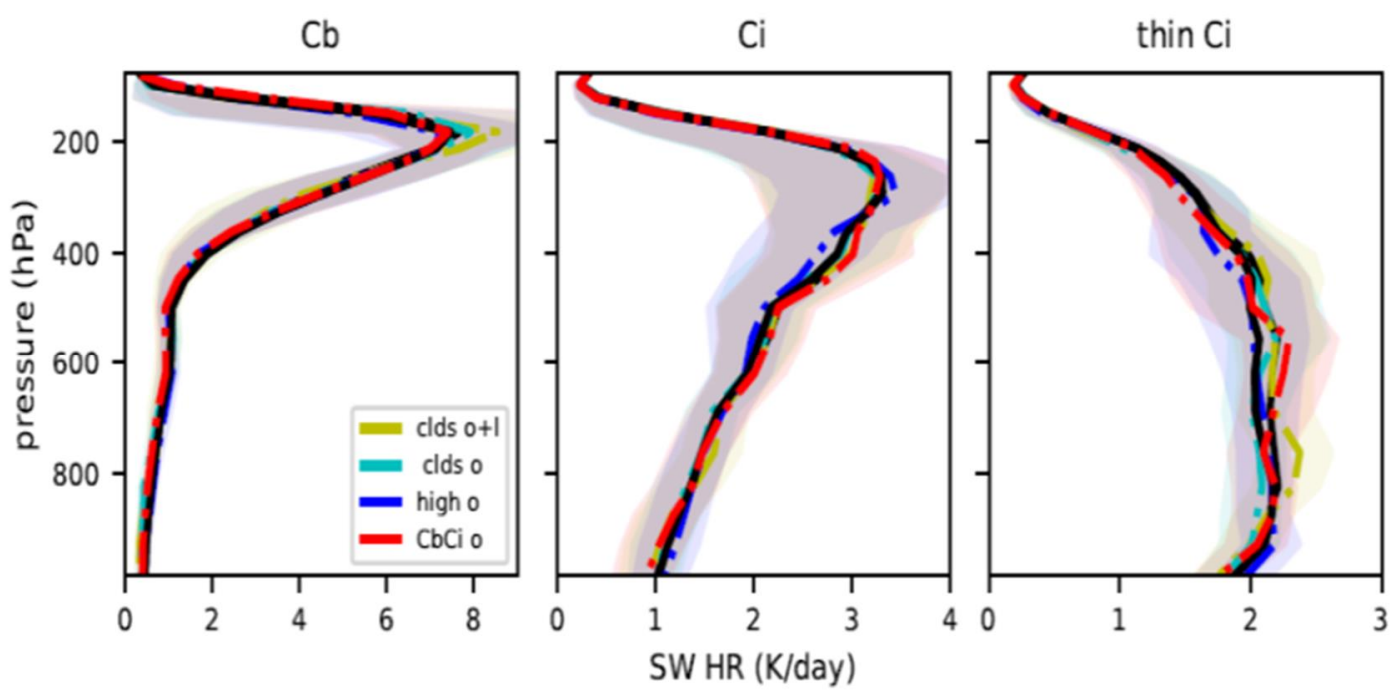

Figure S4: Sensitivity results concerning training over different scenes (high clouds over ocean, all clouds over ocean and all clouds over ocean and land) for the prediction of high-level cloud $L W$ radiative heating rates (above) and SW radiative heating rates (below): predicted vertical profiles compared to those from CALIPSO-CloudSat (black lines), separately for Cb, Cirrus and thin Cirrus, as identified by AIRS-CIRS, over tropical ocean. 30\% and 70\% quantiles of the distributions are also shown. 


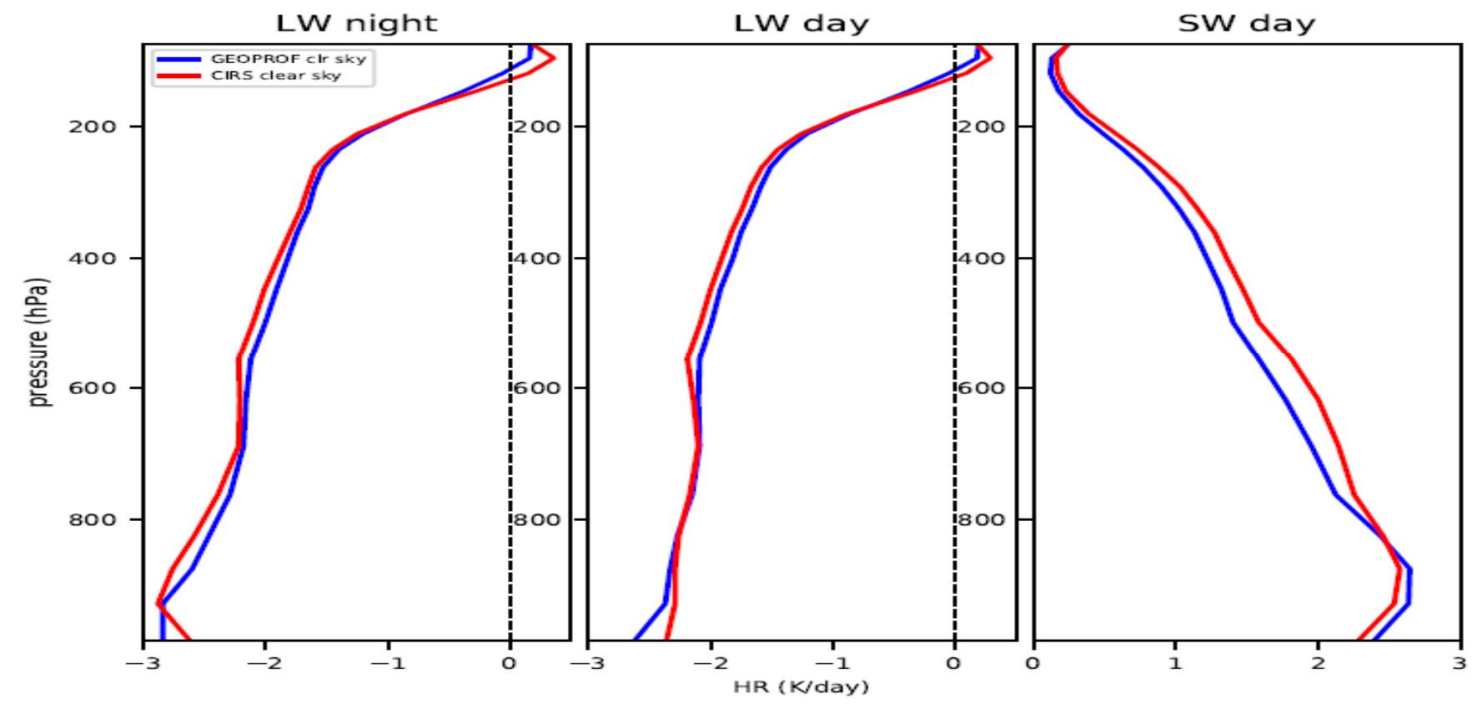

50 Figure S5: Bias in LW and SW heating rates due to uncertainties in clear sky identification. Compared are clear sky identification from CloudSat-lidar GEOPROF (blue) and álear sky ï partly cloudyôidentification from AIRS using the CIRS á posterioriôcloud detection (red).

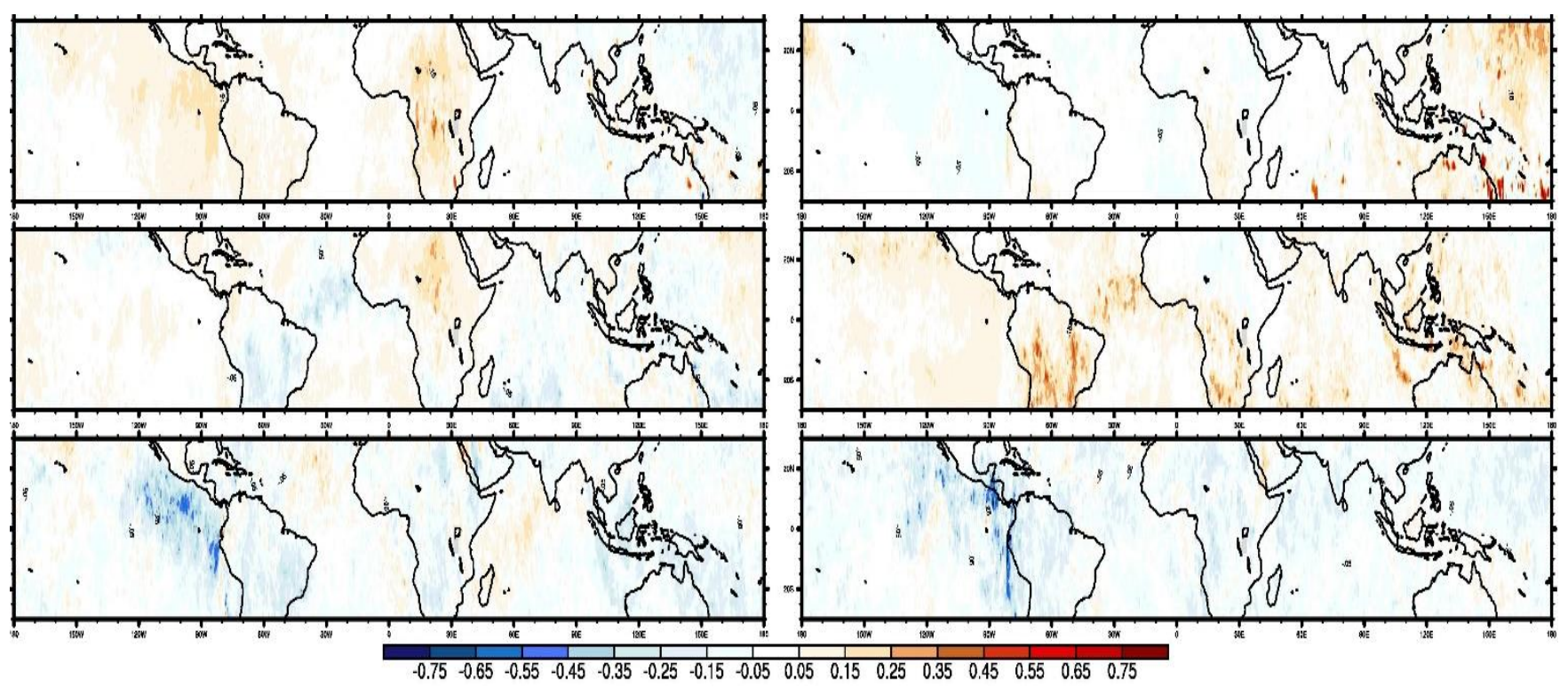

Figure S6: LW heating rate differences in 3 layers (106-131 hPa, 200-223 hPa, 525-585 hPa) between combination of (left) 4 models (clouds over ocean, clouds over land, clear sky over ocean, clear sky over land) and of 2 models (clouds and clear sky) and (right) 8 models and 4 models (clouds over ocean, clouds over land, clear sky over ocean, clear sky over land). 
60

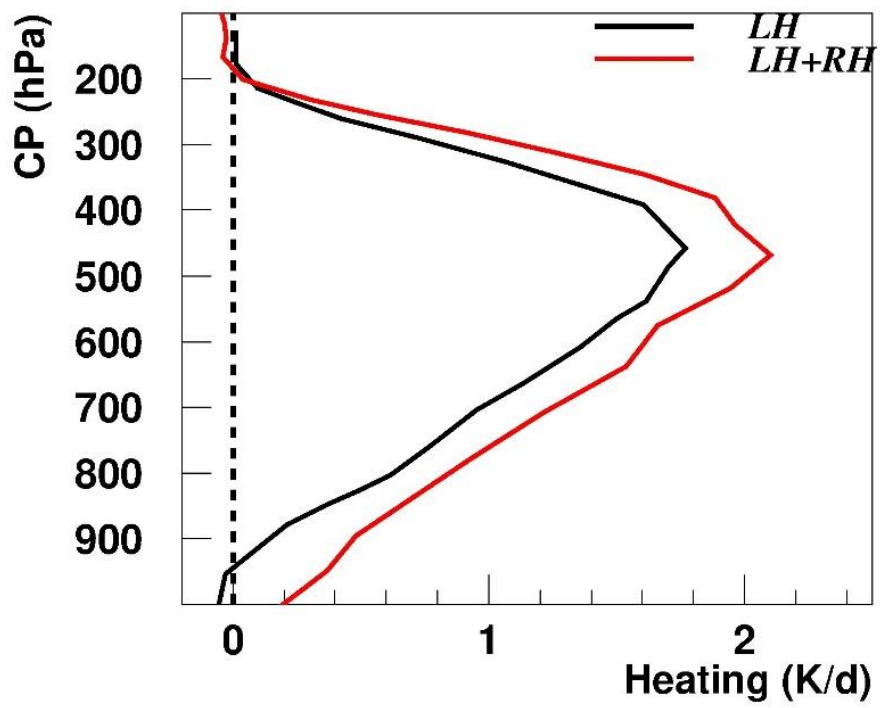

Figure S7: Tropical mean latent heating (black), digitized from Figure 9 of Li et al. (2013), and tropical mean diabatic heating (red) as the sum of latent heating and net radiative heating (from Figure 5). 

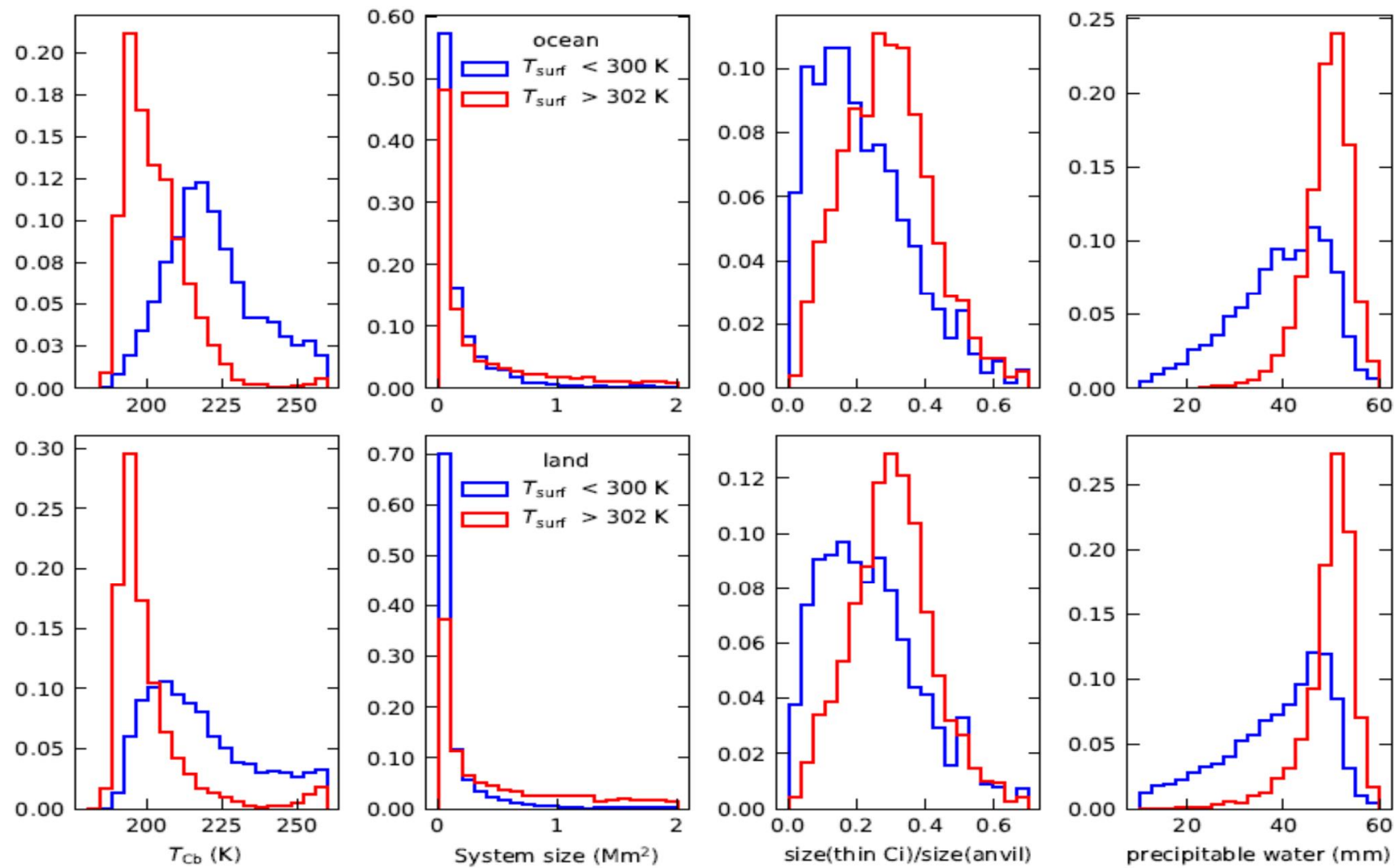

Figure S8: Normalized distributions of properties of the tropical MCSs (temperature of convective core, cloud system size, relative size of the thin cirrus within or surrounding the anvil) and atmospheric precipitable water, separately for systems with a smaller and a larger underlying surface temperature, over ocean (above) and over land (below), at 1:30 AM LT. 



Figure S9: Tropical mean cloud net radiative heating effect (magenta) within the troposphere at 1:30 AM LT (top) and at 1:30 PM LT (bottom), and separately the effect of low- and mid-level clouds (red), mesoscale convective systems (blue), thin cirrus (cyan) and all UT cloud systems (black), averaged over $15 \mathrm{~N}$ to $15 \mathrm{~S}$, when clouds or the specific cloud types are present. Left: regions with $T_{\text {surf }}<300 \mathrm{~K}$, right: regions with $T_{\text {surf }}>302 \mathrm{~K}$. 

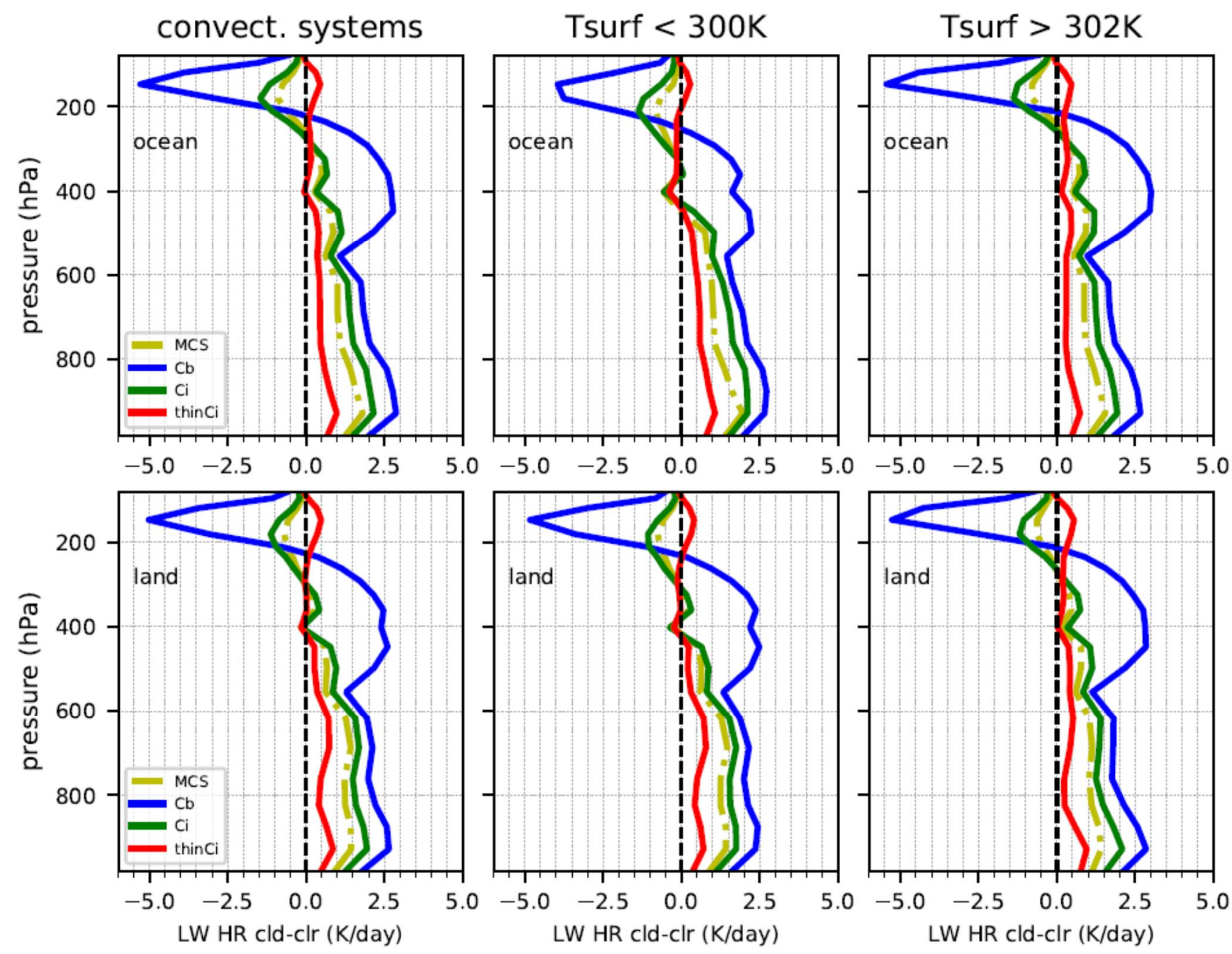

80 Figure S10: Mean net radiative heating effect of MCSs, when present, and their convective cores $(\mathrm{Cb})$, cirrus anvil (Ci) and surrounding thin cirrus (thinCi) over ocean (top) and over land (with $\mathrm{p}_{\text {surf }}>900 \mathrm{hPa}$, bottom), at 1:30 AM local time. In addition, MCSs with the $25 \%$ warmest areas of $T_{\text {surf }}<300 \mathrm{~K}$ and of $T_{\text {surf }}>302 \mathrm{~K}$ are distinguished (from left to right). Statistics of 15 years (2004-2018). 

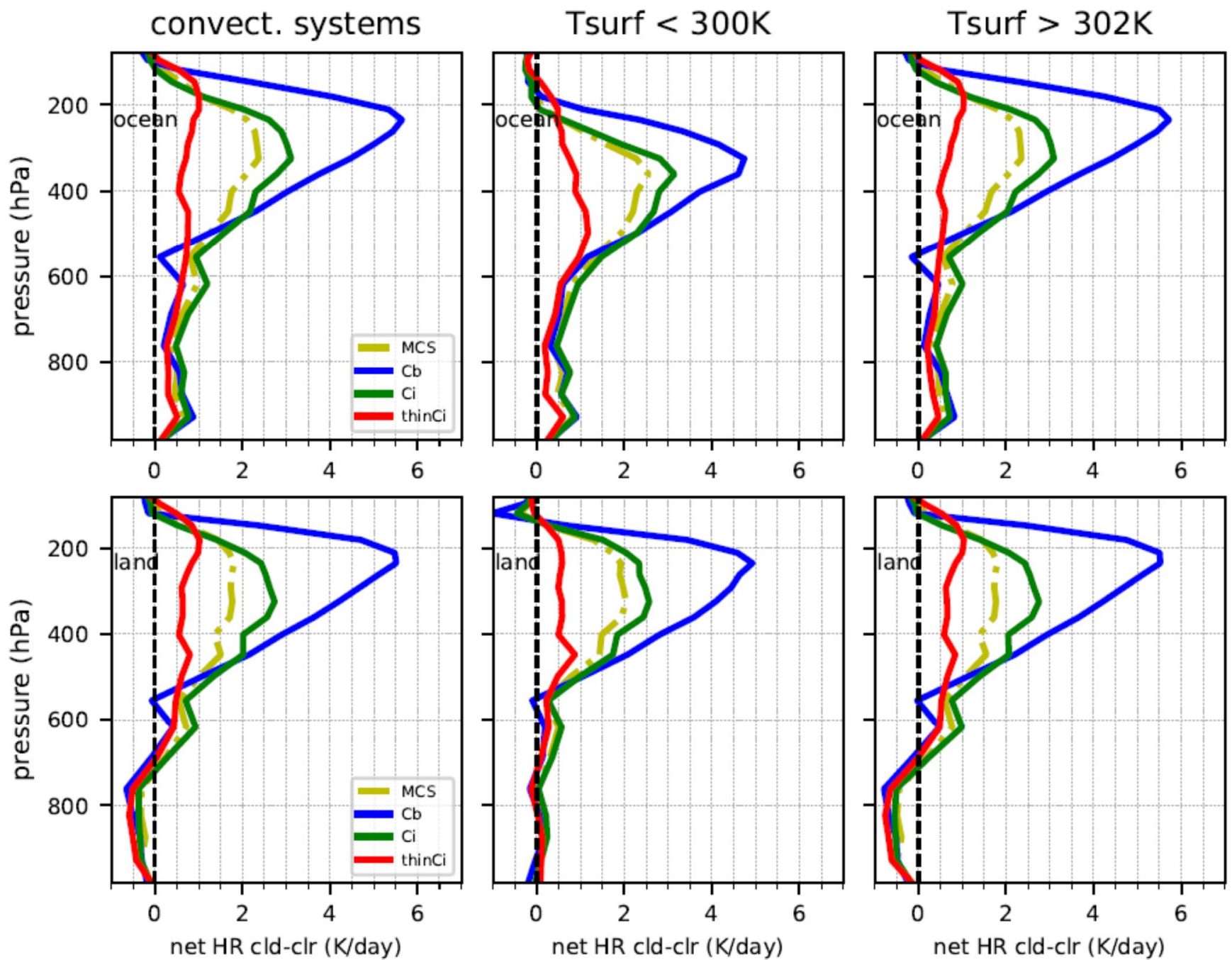

85 Figure S11: Mean net radiative heating effect of MCSs, when present, and their convective cores $(\mathrm{Cb})$, cirrus anvil (Ci) and surrounding thin cirrus (thinCi) over ocean (top) and over land (with $\mathrm{p}_{\text {surf }}>900 \mathrm{hPa}$, bottom), at 1:30 PM local time. In addition, situations with the $25 \%$ warmest areas of $\mathrm{T}_{\text {surf }}<300 \mathrm{~K}$ and of $\mathrm{T}_{\text {surf }}>302 \mathrm{~K}$ are distinguished (from left to right). Statistics of 15 years (2004-2018). 



net $\mathrm{HR}(\mathrm{tCi}-\mathrm{Ci}) /$ dist (K/dayMm)

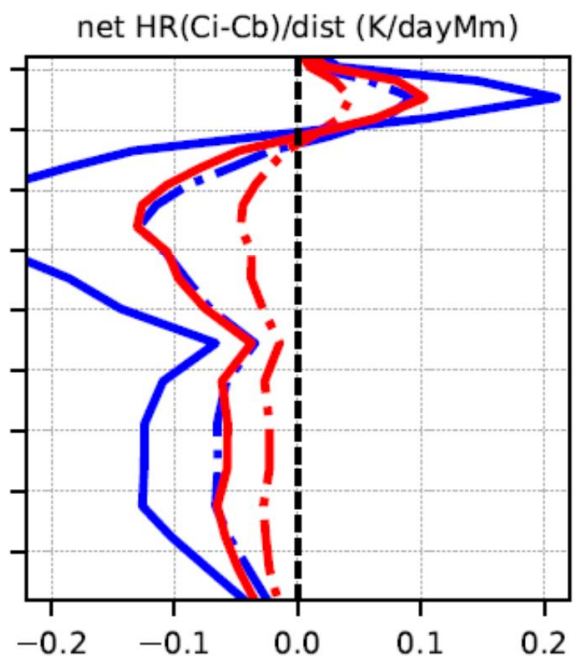

Figure S12: Difference of mean net radiative heating between cirrus anvil and convective cores (top) and between surrounding thin cirrus and cirrus anvil (bottom), divided by the distance between the centers of these MCS parts, assuming circular systems, for MCSs with the $25 \%$ warmest areas of $T_{\text {surf }}<300 \mathrm{~K}$ and of $T_{\text {surf }}>302 \mathrm{~K}$, respectively. Compared are all MCSs, defined as UT cloud systems with at least one convective core, and those with only one convective core with a coverage within the MCS of at least $5 \%$. Left: ocean, right: land. Statistics of 15 years (2004-2018), averaged over $15 \mathrm{~N}$ to $15 \mathrm{~S}$. 

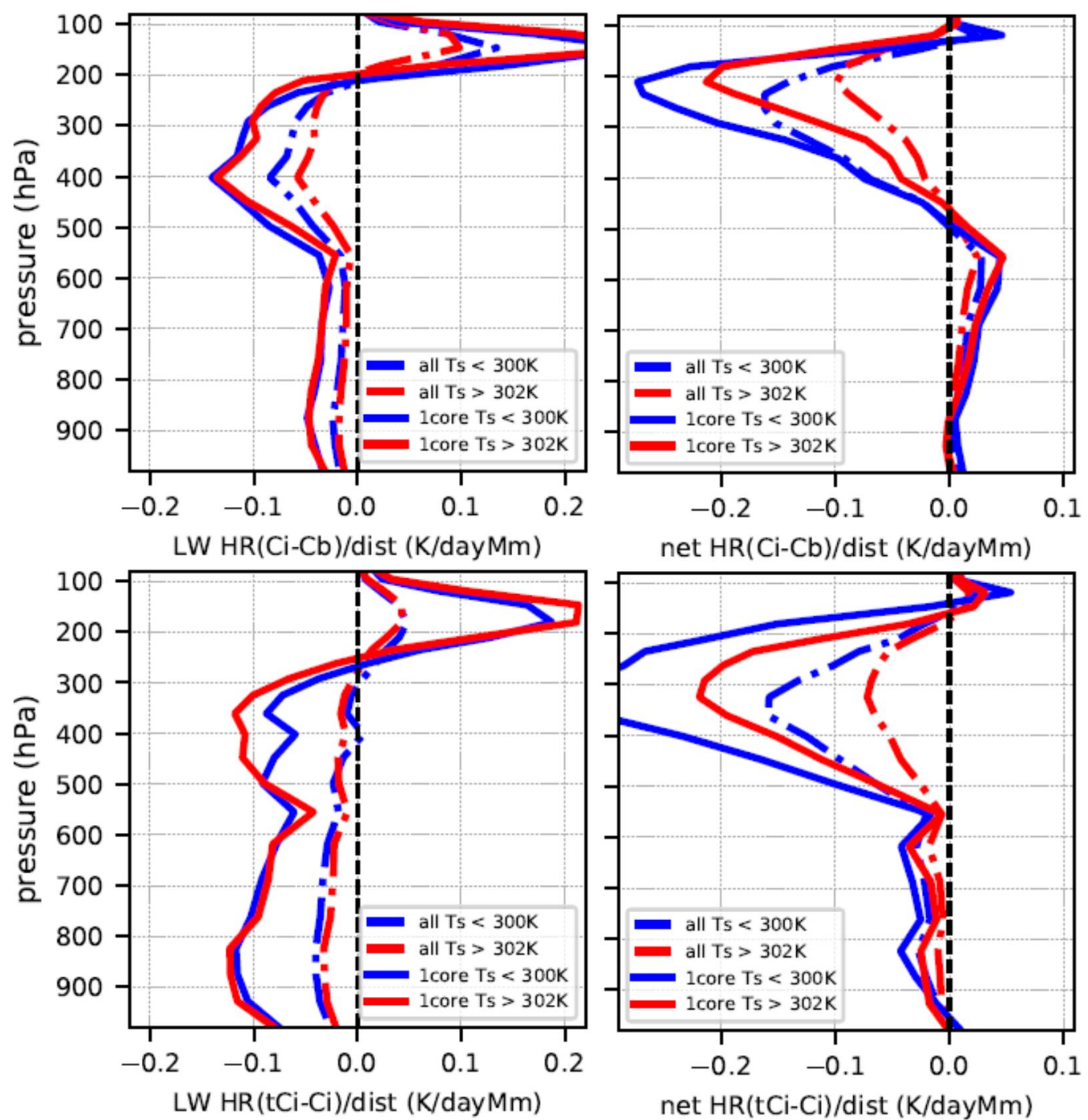

Figure S13: Difference of mean net radiative heating between cirrus anvil and convective cores (top) and between surrounding thin cirrus and cirrus anvil (bottom), divided by the distance between the centers of these MCS parts, assuming circular systems, for MCSs with the $25 \%$ warmest areas of $T_{\text {surf }}<300 \mathrm{~K}$ and of $T_{\text {surf }}>302 \mathrm{~K}$, respectively. Compared are all MCSs, defined as UT cloud systems with at least one convective core, and those with only one convective core with a coverage within the MCS of at least $5 \%$. Left: 1:30 AM LT, right: 1:30 PM LT. Statistics of 15 years (2004-2018), averaged over 15N to 15S. 


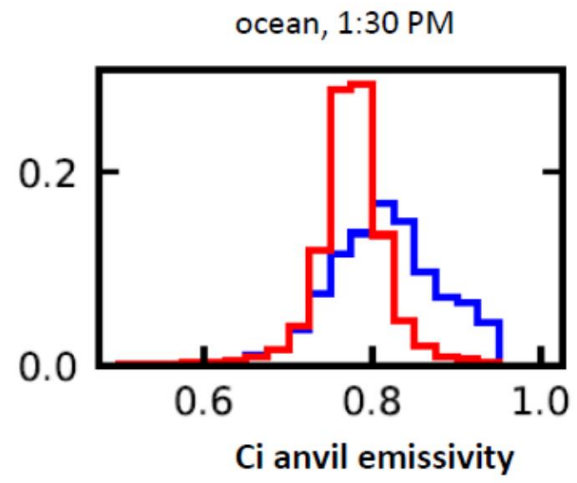

land, 1:30 PM

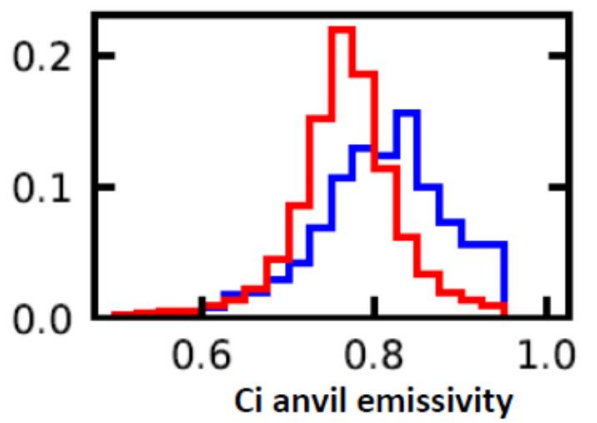

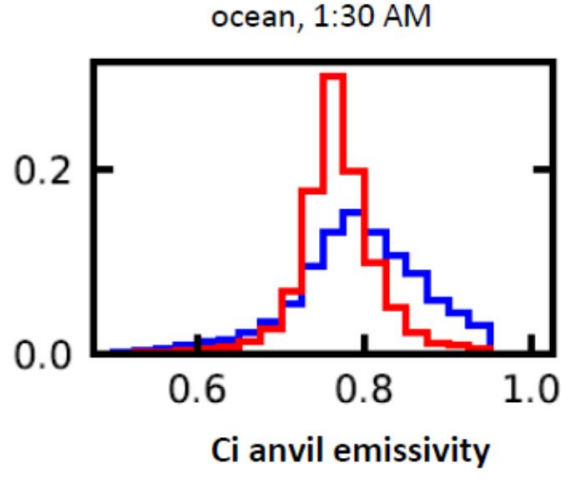

land, 1:30 AM

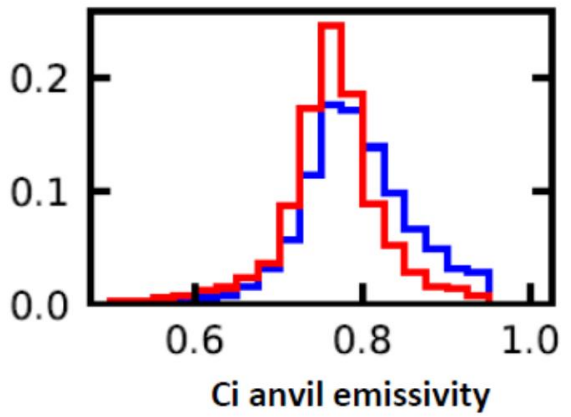

105 Figure S14: Normalized distributions of mean Ci anvil emissivity of the tropical MCSs, separately for systems with a smaller $(\mathrm{Ts}<300 \mathrm{~K})$ and a larger $(\mathrm{Ts}>302 \mathrm{~K})$ underlying surface temperature. 


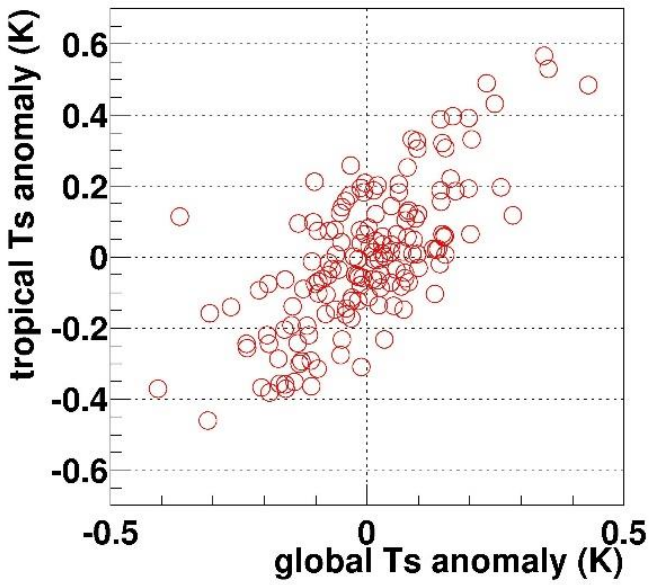

110

Figure S15: Relationship between tropical and global surface temperature anomalies, from ERA-Interim. Monthly statistics from 2003 to 2015. 